\title{
Nipple-Sparing Mastectomy with Primary Implant Reconstruction: Surgical and Oncological Outcome of 435 Breast Cancer Patients
}

\author{
Zoran Radovanovic ${ }^{a, b}$ Milan Ranisavljevic ${ }^{a, b}$ \\ Tatjana Ivkovic-Kapicla, b Nenad Solajic ${ }^{a, b}$ \\ ${ }^{a}$ Faculty of Medicine, University of Novi Sad, Novi Sad, Serbia; \\ ${ }^{b}$ Oncology Institute of Vojvodina, Sremska Kamenica, Serbia
}

\author{
Dragana Radovanovic ${ }^{a, b}$ Ferenc Vicko ${ }^{a, b}$
}

\author{
Keywords \\ Breast cancer - Nipple-sparing mastectomy . \\ Complications · Oncological outcome
}

\section{Summary}

Background: This study aimed to examine the incidence of surgical complications associated with nipple-sparing mastectomy (NSM) with primary implant reconstruction, analyze risk factors for early and late surgical complications of NSM, and determine the incidence of local recurrences and the safety of sparing the nipple-areola complex (NAC). Methods: This retrospective cohort study included 435 patients with 441 NSM procedures over a period of 9 years (2004-2012). All surgical complications and the oncological outcome were recorded during follow-up. Results: The most common early surgical complication was skin flap ischemia/necrosis (26 patients, 5.9\%). Prosthesis explantation due to complications was carried out in $11(2.5 \%)$ cases. Neoadjuvant chemotherapy, implant size $>500 \mathrm{ml}$, diabetes mellitus, body mass index $>25 \mathrm{~kg} / \mathrm{m}^{2}$, and incisions other than lateral were risk factors for early complications ( $p$ $<0.001$ ). The NAC excision rate was $5.4 \%$ (24 cases) due to confirmed presence of cancer cells in the subareolar tissue. Capsular contracture as a late complication occurred in $33(7.48 \%)$ cases. Local relapse occurred in 32 (7.3\%) patients. Distant metastases were diagnosed in 68 $(15.6 \%)$ patients, and $53(12.2 \%)$ patients died during the follow-up period. Conclusions: NSM with immediate implant reconstruction has an acceptable morbidity rate and is an oncologically and surgically appropriate treatment for most women requiring mastectomy.

(c) 2018 S. Karger GmbH, Freiburg

\section{Introduction}

Nipple-sparing mastectomy (NSM) has been proven to be an oncologically safe procedure in breast cancer surgery [1-4]. With primary implant reconstruction, NSM has become the best treatment option for women requiring mastectomy due to better cosmetic result, greater satisfaction, and better quality of life compared to modified radical mastectomy or skin-sparing mastectomy $[5,6]$. Breast reconstructions are subject to possible early postoperative complications related to either wound healing or flap viability that can lead to prolonged convalescent periods, albeit without causing significant delays in adjuvant chemotherapy or radiotherapy [7-9]. Although rare, serious complications usually require another surgery and can lead to implant loss. The procedure appears to be oncologically safe for appropriately selected patients, but additional long-term follow-up is needed especially in patients with advanced stages of disease [10].

This study presents a single-institution experience in primary breast reconstruction with implants following NSM. Our aims were to examine the incidence of surgical complications of NSM with primary implant reconstruction, analyze risk factors for early and late surgical complications of NSM, and determine the incidence of local recurrences and the safety of sparing the nipple-areola complex (NAC).

\section{KARGER}

() 2018 S. Karger GmbH, Freiburg 


\section{Material and Methods}

This retrospective cohort study was approved by the ethics committee of the Oncology Institute of Vojvodina and included 435 patients ( 6 with bilateral surgery) with 441 NSM procedures over a period of 9 years (2004-2012). The study included breast cancer patients with NSM and primary reconstruction performed as initial procedure or after previous breast-conserving surgery (BCS) or neoadjuvant chemotherapy.

Before surgery, patients were counselled about the procedure, oncological safety, risks of early and late complications, risk of NAC removal in the case of cancer cells being detected in the tissue beneath the nipple, and postoperative esthetic expectations. Routine preoperative diagnostics included clinical examination, ultrasonography, mammography (magnetic resonance mammography in some cases), and core biopsy.

Mastectomy was usually performed via lateral incision (358 cases, $81.2 \%$ ) extended to the upper outer quadrant, thereby allowing axillary access for sentinel node (SN) biopsy or axillary clearance. Other types of incisions were used only in cases with previous excisional biopsy or BCS in an attempt to incorporate the previous incision into the NSM incision (83 cases, 18.8\%).

The breast volume, consisting of the breast tissue and fat, was entirely removed, except for the part under the NAC. Subareolar tissue was excised and sent off for frozen section analysis. The NAC was preserved when no malignant cells were identified in the frozen sections.

Primary breast reconstruction was performed with contoured profile gelfilled prostheses (Mentor Contour Profile ${ }^{\circledR}$, fixed-volume implants; Irvine, CA, USA) placed into the muscle pocket formed by the pectoralis major and the serratus anterior muscle. The goal was to maintain the natural breast contour, volume, and position.

For tumors smaller than $3 \mathrm{~cm}$, and in some cases of high-grade ductal carcinoma in situ (DCIS), SN biopsy was performed as standard procedure with intraoperative frozen section analysis. Axillary clearance (levels I and II) was performed if SN biopsy revealed metastases and in all cases of invasive multicentric breast cancers, tumors over $3 \mathrm{~cm}$, and local recurrences after BCS with previously performed SN biopsy. If NSM was performed due to local recurrence after previous BCS with axillary clearance, staging was assessed according to the histopathology of the first operation.

In the case of minor complications, patients were followed up every week after hospital discharge. Regular follow-ups by the surgeon and the medical oncologist were carried out every 3 months during the first year, and then every 6 months during the second and the third year. Thereafter, appointments for check-ups were made once a year.

All early and late surgical complications and the oncological outcome were recorded. Skin flap ischemia/necrosis $<2 \mathrm{~cm}^{2}$ was recorded as a minor event, while larger areas of ischemia/necrosis were regarded as a major complication. Infections treated with oral antibiotics were rated as minor, while those requiring parenteral administration of antibiotics were considered major infections.

Statistical analysis was performed with SPSS v.16 (IBM Corp., Armonk, NY, USA) using t-test for continuous variables, Kaplan-Meier for overall survival estimates, and Pearson's chi-squared and Fisher's exact test for categorical variables assuming that the results for the 2 breasts of the same woman are independent. The level of significance was set at 0.05 .

\section{Results}

The mean patient age was 49 years (range 25-75 years, standard deviation (SD) 9.59); the mean follow-up period was 79 months (range 34-141 months, SD 27.7).

Surgery was the primary treatment for breast cancer in 252 (57.93\%) patients. 117 (26.9\%) patients were operated on after neoadjuvant chemotherapy, while $66(15.17 \%)$ patients had previously received BCS followed by adjuvant treatment (radiotherapy with or
Table 1. Indications for nipple-sparing mastectomy (NSM)

\begin{tabular}{lc}
\hline Indication for NSM & $\mathrm{n}(\%)$ \\
\hline $\begin{array}{l}\text { Size of invasive cancer } \\
\quad \text { (tumor/breast size ratio) }\end{array}$ & $117(26.5)$ \\
$\begin{array}{l}\text { Multicentric cancer } \\
\text { Extensive ductal carcinoma }\end{array}$ & $194(44)$ \\
$\quad$ in situ (DCIS) & $23(5.2)$ \\
Local recurrence after & $67(15.2)$ \\
$\quad$ breast-conserving surgery & \\
Invasive cancer + DCIS & $40(9.1)$ \\
Total & $441(100)$
\end{tabular}

Table 2. Staging and treatment

\begin{tabular}{lc}
\hline Variable & $\mathrm{n}(\%)$ \\
\hline Stage & \\
0 & $22(5.1)$ \\
I & $95(21.8)$ \\
IIA & $102(23.4)$ \\
IIB & $95(21.8)$ \\
IIIA & $80(18.4)$ \\
IIIB & $18(4.1)$ \\
IIIC & $23(5.3)$ \\
\hline Tumor histology & \\
Ductal & $309(70.1)$ \\
Lobular & $89(20.2)$ \\
Other & $43(9.1)$ \\
\hline Axillary evaluation & \\
Sentinel lymph node (SN) procedure & $55(12.5)$ \\
Axillary dissection & $313(71)$ \\
Axillary dissection after SN biopsy & $21(4.8)$ \\
Not assessed (some cases of ductal carcinoma in situ) & $12(2.7)$ \\
Previous axillary clearance during breast-conserving & $40(9.1)$ \\
$\quad$ surgery & \\
\hline Nipple-areola complex removal & \\
Yes & \\
No & $324(73.5)$ \\
\hline Neoadjuvant chemotherapy & \\
Yes & \\
No & \\
\hline & \\
\hline
\end{tabular}

without adjuvant chemotherapy) and were undergoing surgery due to local recurrence. Implant sizes were between 120 and $775 \mathrm{ml}$ (mean $347 \mathrm{ml}$, median $345 \mathrm{ml}$, SD 144.9).

Indications for mastectomy are presented in table 1 , and stage and treatment in table 2.

An SN procedure was carried out in 77 patients, with $56 \mathrm{SN}$ negative and $21 \mathrm{SN}$-positive patients requiring axillary clearance. Overall, axillary clearance was performed in 334 (75.7\%) patients, and in $51(11.56 \%)$ cases clearance had been performed during previous $\mathrm{BCS}$. 


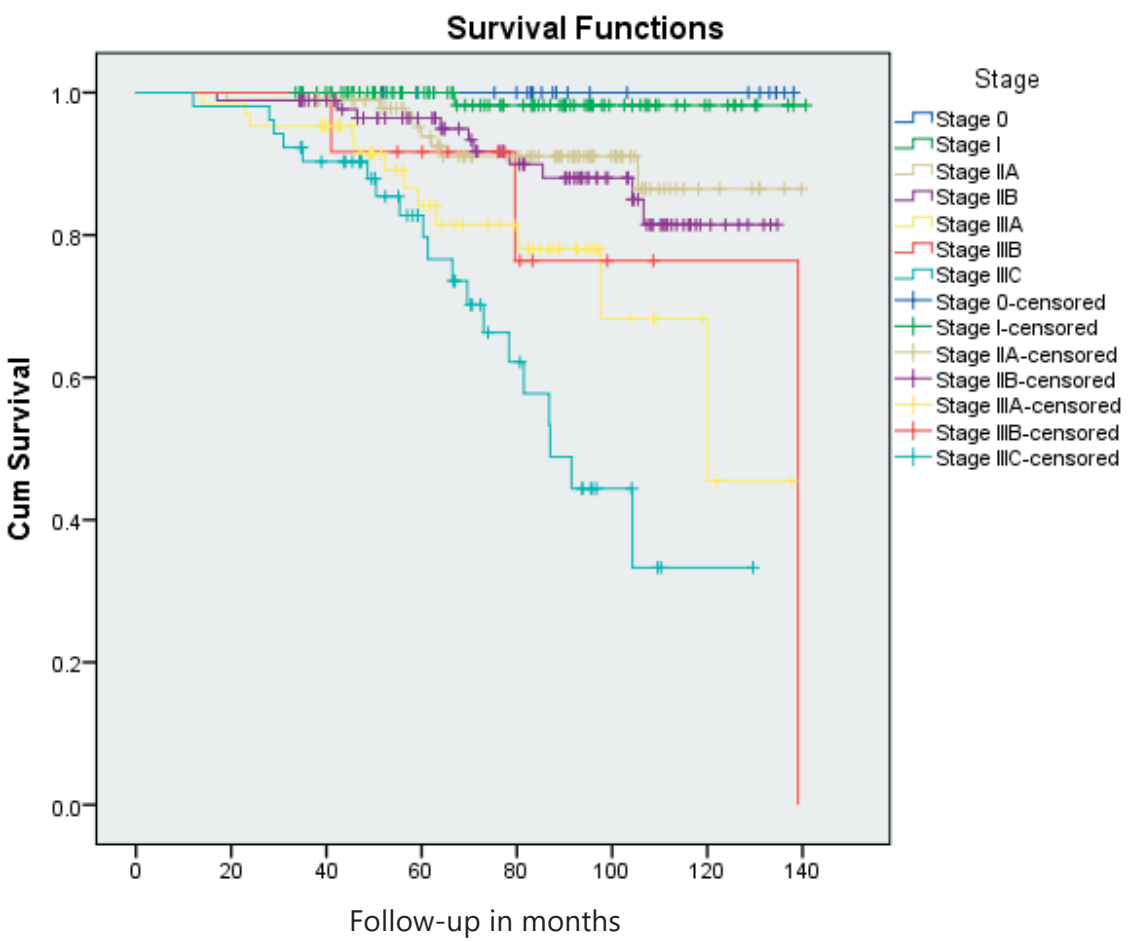

Table 3. Early and late complications of nipple-sparing mastectomy

\begin{tabular}{lc}
\hline Complication & Procedures, $\mathrm{n}(\%)$ \\
\hline No complication & $377(85.4)$ \\
Epidermolysis & $2(0.5)$ \\
Nipple-areola complex necrosis & $1(0.2)$ \\
Minor infection & $8(1.8)$ \\
Major infection & $7(1.6)$ \\
Minor skin ischemia/necrosis & $11(2.5)$ \\
Major skin ischemia/necrosis & $12(2.7)$ \\
Prolonged seroma formation & $13(2.95)$ \\
Wound dehiscence & $1(0.2)$ \\
Hematoma & $3(0.2)$ \\
Lateral mobilization of prosthesis & $5(1.1)$ \\
Capsular contracture & $33(7.48)$ \\
Total & $441(100)$ \\
\hline
\end{tabular}

The NAC excision rate was $5.4 \%$ (24 cases) due to confirmed presence of cancer cells in the subareolar tissue by frozen section analysis or on final histology.

Of all patients, $83(18.82 \%)$ were smokers, 27 (6.1\%) had diabetes mellitus (DM), and 29 (6.6\%) had a body mass index (BMI) of $>30 \mathrm{~kg} / \mathrm{m}^{2}$.

Early and late postoperative complications were noted in 64 (14.51\%) procedures (table 3). The most common complication was skin flap ischemia/necrosis (26 patients, 5.2\%). Most ischemic complications were treated conservatively $(22 / 26)$, while 4 cases required surgical excision of the necrotic skin with primary suturing and, in 1 case, with latissimus dorsi flap reconstruction. In the perioperative period, only $1(0.2 \%)$ case experienced NAC necrosis.

Delayed oncological treatment (which started between 6 and 12 weeks after NSM) due to early surgical complications occurred in only $11(2.5 \%)$ patients.

Capsular contracture, as a late complication, occurred in 33 (7.48\%) cases. All of these patients had irradiation as part of their adjuvant treatment. The severity of capsular contracture was estimated according to the Baker classification (10 cases grade II, 15 grade III, and 8 cases grade IV). 16 patients underwent capsulotomy with re-implantation of the prosthesis.

Prosthesis explantation due to complications was necessary in 11 (2.5\%) cases; the main reason was infection ( 9 cases), and 2 patients expressed the wish to have the silicone implant removed due to chronic chest pain and discomfort. In 15 cases, prosthesis explantation was needed due to local recurrence requiring mastectomy.

Neoadjuvant chemotherapy, implant size $>500 \mathrm{ml}$, DM, BMI $>25 \mathrm{~kg} / \mathrm{m}^{2}$, and incisions other than lateral were risk factors for early complications $(\mathrm{p}<0.001)$. Smoking and irradiation (patients with previous BCS) had no impact on the early surgical complication rate.

During follow-up, local relapse occurred in 32 (7.3\%) patients, with 3 cases in stage I, 10 cases in stage II, and 19 cases in stage III and a mean time to recurrence of 21 months. 2 recurrences were in the NAC. Distant metastases were diagnosed in 68 (15.6\%) patients, and $53(12.2 \%)$ patients died during the follow-up period (fig. 1). 


\section{Discussion}

In 1962, Freeman [11] first reported the technique of subcutaneous mastectomy followed by reconstruction. Techniques have evolved since that time and today comprise the use of prosthetic materials, autologous tissue, or a combination thereof [12]. The cosmetic outcome of reconstruction with implant after postoperative radiotherapy is not always satisfactory because of capsular contracture and skin changes due to irradiation [13]. For that reason, Petit et al. [14] suggested the concept of NSM followed by intraoperative radiotherapy and immediate reconstruction. Some authors consider autologous reconstruction to be the best option due to better esthetic result compared to implant reconstructions [15]. The latissimus dorsi myocutaneous flap was the method of choice for autologous tissue breast reconstruction until the introduction of the transverse rectus abdominis musculocutaneous (TRAM) flap in 1982 [16]. The advantage of the TRAM flap is the provision of an adequate soft tissue bulk to produce a satisfactory breast shape and yield a permanent lifelong result. Many other flaps and techniques can be used in primary and secondary autologous breast reconstructions, but most of them are demanding on both the patient and the surgeon [12]. Therefore, subpectoral implantation of silicone prostheses after NSM has become a widely used method for breast reconstruction, and compared to autologous tissue reconstructions it is a technically less demanding procedure with shorter operating, hospitalization, and recovery times [17].

\section{Surgical Complications}

The surgical outcome of NSM is not always predictable. Concerns are mostly related to increased early postoperative complications such as infection, wound healing problems, and ischemia or necrosis of the skin or NAC [18-20]. Age, skin incision, flap thickness, reconstruction type, smoking, neoadjuvant chemotherapy, preoperative irradiation, and comorbidities have been reported as risk factors for ischemic complications concerning the skin and NAC [1-4, 18, 19, 21-26]. Patients with an increased BMI and DM are likely to have additional complications due to associated vascular disease [25].

Neoadjuvant chemotherapy is gaining acceptance as an option for locally advanced breast cancer treatment but was found to be a risk factor for early surgical complications in our study. However, other authors did not confirm a relationship between neoadjuvant chemotherapy and surgical complications [27, 28].

The rate of NAC and breast skin necrosis is usually less than $10 \%[19,21]$. We identified 26 (5.90\%) patients with necrotic complications with only $1(0.2 \%)$ NAC necrosis. Komorowski et al. [19] in their analysis of $38 \mathrm{NSM}$ had $15.8 \%$ necrotic complications, and only age $>45$ years had a statistical impact on skin necrosis. They used a periareolar omega-shaped approach in $79 \%$ of cases. In our study, incisions other than lateral were a risk factor for skin ischemia/necrosis. We believe that periareolar incisions might compromise the blood supply and thus prefer lateral incisions as was also suggested by some other authors [29, 30]. After removal of the glandular breast tissue under the dermis, the NAC and the skin are poorly vascularized by the dermal vessel network. Nipple microvessels and their position to the lactiferous ducts where thoroughly analyzed by Rusby et al. [31]. The mean duct bundle diameter in microscopic sections was $5.2 \mathrm{~mm}$. According to their study, in a non-irradiated nipple, leaving a 2-mm rim of peripheral nipple tissue retains $50 \%$ of the vessels of the nipple cross section with complete excision of the duct bundle in $96 \%$ of cases, while a thicker peripheral rim of $3 \mathrm{~mm}$ retains $66 \%$ of vessels but with complete duct excision in $87 \%$ cases. This study shows that the surgeon is forced to make a compromise between removal of all duct tissue and the preservation of blood vessels to maintain the viability of the nipple remnant. In our study, breast irradiation (in patients with previous BCS) was not associated with skin ischemic complications.

Capsular contracture is the most frequent late complication and a major cause of poor cosmetic outcome. We observed a capsular contracture rate of $7.48 \%$, similar to other series $[32,33]$. In a study by Contant et al. [34], capsular contracture was seen significantly more often around prostheses implanted in a previously irradiated area $(\mathrm{p}<0.0005)$, and irradiation after NSM was associated with a significant increase in capsular contracture $(\mathrm{p}=0.001)$. Pinsolle et al. [35] also confirmed an impact of radiotherapy on the capsular contracture rate. A number of studies suggested that hematoma and peri-prosthetic bacterial contamination may also be associated with a higher incidence of capsular contracture [36-39].

An explantation rate due to complications of only $2.5 \%$ in our study and delayed oncological treatment due to complications in $2.5 \%$ of patients suggests the safety of the procedure.

\section{Oncological Safety of NSM}

The NAC excision rate in our study was $5.4 \%$ ( 24 cases) due to confirmed presence of cancer cells in subareolar tissue by frozen section analysis or on final histology. Histological studies showed that nipple involvement ranges from $5 \%$ to as much as $58 \%$ depending on the size of the primary breast tumor, location, multicentricity, lymph node positivity, and presence of an extensive intraductal component [40-42]. Gulben et al. [41], in a multivariate logistic regression analysis, showed that tumor location (central vs. peripheral; $\mathrm{p}<0.0001)$, number of positive axillary lymph nodes ( $\geq 10$ vs. $<10 ; p<0.005)$, and lymphatic vascular invasion (yes vs. no; $\mathrm{p}<0.0001$ ) were the most important prognostic factors for NAC involvement and that patients with 2 or 3 risk factors should be considered at high risk for cancer involvement of the NAC.

In our series, $121(27.8 \%)$ patients had stage III breast cancer. NSM in locally advanced breast cancer is not contraindicated if surgery is radical and adjuvant treatment starts in time. Although patients with locally advanced disease have a poorer prognosis, they deserve to be given the same treatment options as early-stage patients. Avoiding immediate reconstructive methods in this group of patients merely for economic reasons is not justified. In a study of 146 women with primary reconstruction, the risks of distant metastasis and breast cancer-related death were signifi- 
cantly lower in the breast reconstruction group than in the control group treated with mastectomy. The risks of local recurrence, second breast cancers, and second primary cancers at a site other than the breast were not significantly different between the 2 groups [43]. In the report by Spiegel et al. [44] with a mean follow-up of 9.8 years in 221 patients after SSM with immediate reconstructions, the incidence of local recurrence was $5.6 \%$ for invasive cancer and $0 \%$ for DCIS. The metastatic recurrence rate in the invasive carcinoma group was $6.8 \%$. In this cohort, local recurrence appeared in $7.3 \%$ of patients, mostly with stage III cases. Hence, according to our results and those of other authors, the risk of local recurrence in NSM is even lower than in BCS, confirming the oncological safety of NSM with primary reconstruction $[9,45,46]$.

\section{Conclusion}

Based on well-planned surgical technique, NSM with primary implant reconstruction is an oncologically and surgically appropriate treatment for most women requiring mastectomy. Risk factors for surgical complications and NAC involvement have to be carefully discussed preoperatively by a multidisciplinary team. The patient has to understand the risks related to the procedure, especially in terms of immediate surgical complications, esthetic outcome, and the possible need for revisional surgery.

\section{Disclosure Statement}

The authors declare that they have no competing interests.

\section{References}

1 Krajewski AC, Boughey JC, Degnim AC, et al: Expanded indications and improved outcomes for nipple-sparing mastectomy over time. Ann Surg Oncol 2015; 22: 33173323

2 Tang R, Coopey SB, Colwell AS, et al: Nipple-sparing mastectomy in irradiated breasts: selecting patients to minimize complications. Ann Surg Oncol 2015; 22: 3331-3337.

3 Frederick MJ, Lin AM, Neuman R, et al: Nipple-sparing mastectomy in patients with previous breast surgery: comparative analysis of 775 immediate breast reconstructions. Plast Reconstr Surg 2015; 135: 954e-962e.

$4 \mathrm{Ou} \mathrm{KW}$, Yu JC, Ho MH, et al: Oncological safety and outcomes of nipple-sparing mastectomy with breast reconstruction: a single-centered experience in Taiwan. Ann Plast Surg 2015; 74(suppl 2):S127-231.

5 Bailey CR, Ogbuagu O, Baltodano PA, et al: Quality-of-life outcomes improve with nipple-sparing mastectomy and breast reconstruction. Plast Reconstr Surg 2017; 140: 219226.

6 Mesdag V, Regis C, Tresch E, et al: Nipple sparing mastectomy for breast cancer is associated with high patient satisfaction and safe oncological outcomes. J Gynecol Obstet Hum Reprod 2017; 46: 637-642.

7 Furey PC, Macgillivray DC, Castiglione CL, Allen L: Wound complications in patients receiving adjuvant chemotherapy after mastectomy and immediate breast reconstruction for breast cancer. J Surg Oncol 1994; 55: 194197.

8 Yule GJ, Concannon MJ, Croll G, Puckett CL: Is there liability with chemotherapy following immediate breast construction? Plast Reconstr Surg 1996; 97: 969-973.

9 Mustonen P, Lepisto J, Papp A, et al: The surgical and oncological safety of immediate breast reconstruction. Eur J Surg Oncol 2004; 30: 817-823.

10 Gerber B, Krause A, Dieterich M, Kundt G, Reimer T: The oncological safety of skin sparing mastectomy with conservation of the nipple-areola complex and autologous reconstruction: an extended follow-up study. Ann Surg 2009; 249: 461-468.

11 Freeman BS: Subcutaneous mastectomy for benign breast lesions with immediate or delayed prosthetic replacement. Plast Reconstr Surg Transplant Bull 1962; 30: 676-682.

12 Malata CM, McIntosh SA, Purushotham AD: Immediate breast reconstruction after mastectomy for cancer. Br J Surg 2000; 87: 1455-1472.

$\checkmark 13$ Vandeweyer E, Deraemaecker R: Radiation therapy after immediate breast reconstruction with implants. Plast Reconstr Surg 2000; 106: 56-58; discussion 59-60.
Petit JY, Veronesi U, Orecchia R, et al: Nipple-sparing mastectomy in association with intra operative radiotherapy (ELIOT): a new type of mastectomy for breast cancer treatment. Breast Cancer Res Treat 2006; 96: 47-51.

15 Alderman AK, Wilkins EG, Lowery JC, Kim M, Davis JA: Determinants of patient satisfaction in postmastectomy breast reconstruction. Plast Reconstr Surg 2000; 106: 769776.

16 Hartrampf CR, Scheflan M, Black PW: Breast reconstruction with a transverse abdominal island flap. Plast Reconstr Surg 1982; 69: 216-225.

17 Callaghan CJ, Couto E, Kerin MJ, et al: Breast reconstruction in the United Kingdom and Ireland. Br J Surg 2002; 89: $335-340$.

18 Tokin C, Weiss A, Wang-Rodriguez J, Blair SL: Oncologic safety of skin-sparing and nipple-sparing mastectomy: a discussion and review of the literature. Int J Surg Oncol 2012; 2012: 921821

19 Komorowski AL, Zanini V, Regolo L, et al: Necrotic complications after nipple- and areola-sparing mastectomy. World J Surg 2006; 30: 1410-1413.

20 Radovanovic Z, Radovanovic D, Golubovic A, et al: Early complications after nipple-sparing mastectomy and immediate breast reconstruction with silicone prosthesis: results of 214 procedures. Scand J Surg 2010; 99: 115-118

21 Munhoz AM, Aldrighi CM, Montag E, et al: Clinical outcomes following nipple-areola-sparing mastectomy with immediate implant-based breast reconstruction: a 12-year experience with an analysis of patient and breast-related factors for complications. Breast Cancer Res Treat 2013; 140: 545-555.

22 Poruk KE, Ying J, Chidester JR, et al: Breast cancer recurrence after nipple-sparing mastectomy: one institution's experience. Am J Surg 2015; 209: 212-217.

23 Reish RG, Lin A, Phillips NA, et al: Breast reconstruction outcomes after nipple-sparing mastectomy and radiation therapy. Plast Reconstr Surg 2015; 135: 959-966.

24 Woerdeman LA, Hage JJ, Hofland MM, Rutgers EJ: A prospective assessment of surgical risk factors in 400 cases of skin-sparing mastectomy and immediate breast reconstruction with implants to establish selection criteria. Plast Reconstr Surg 2007; 119: 455-463.

25 Mosahebi A, Ramakrishnan V, Gittos M, Collier J: Aesthetic outcome of different techniques of reconstruction following nipple-areola-preserving envelope mastectomy with immediate reconstruction. Plast Reconstr Surg 2007; 119: 796-803
26 Rodriguez-Feliz J, Codner MA: Embrace the change: incor porating single-stage implant breast reconstruction into your practice. Plast Reconstr Surg 2015; 136: 221-231.

27 Donker M, Hage JJ, Woerdeman LA, et al: Surgical complications of skin sparing mastectomy and immediate prosthetic reconstruction after neoadjuvant chemotherapy for invasive breast cancer. Eur J Surg Oncol 2012; 38: 25-30.

28 Monrigal E, Dauplat J, Gimbergues P, et al: Mastectomy with immediate breast reconstruction after neoadjuvant chemotherapy and radiation therapy. A new option for patients with operable invasive breast cancer. Results of a 20 years single institution study. Eur J Surg Oncol 2011; 37: 864-870.

29 Crowe JP Jr, Kim JA, Yetman R, et al: Nipple-sparing mastectomy: technique and results of 54 procedures. Arch Surg 2004; 139: 148-150.

30 Donovan CA, Harit AP, Chung A, et al: Oncological and surgical outcomes after nipple-sparing mastectomy: do incisions matter? Ann Surg Oncol 2016; 23: 3226-3231.

31 Rusby JE, Brachtel EF, Taghian A, et al: George Peters Award. Microscopic anatomy within the nipple: implications for nipple-sparing mastectomy. Am J Surg 2007; 194: 433-437.

32 Alderman AK, Wilkins EG, Kim HM, Lowery JC: Complications in postmastectomy breast reconstruction: two-year results of the Michigan Breast Reconstruction Outcome Study. Plast Reconstr Surg 2002; 109: 2265-2274.

33 Clough KB, Bourgeois D, Falcou MC, Renolleau C, Durand JC: Immediate breast reconstruction by prosthesis: a safe technique for extensive intraductal and microinvasive carcinomas. Ann Surg Oncol 1996; 3: 212-218.

34 Contant CM, van Geel AN, van der Holt B, et al: Morbidity of immediate breast reconstruction (IBR) after mastectomy by a subpectorally placed silicone prosthesis: the adverse effect of radiotherapy. Eur J Surg Oncol 2000; 26: 344-350.

35 Pinsolle V, Grinfeder C, Mathoulin-Pelissier S, Faucher A: Complications analysis of 266 immediate breast reconstructions. J Plast Reconstr Aesthet Surg 2006; 59: 10171024.

36 Netscher DT, Weizer G, Wigoda P, et al: Clinical relevance of positive breast periprosthetic cultures without overt infection. Plast Reconstr Surg 1995; 96: 1125-1129.

37 Burkhardt BR, Dempsey PD, Schnur PL, Tofield JJ: Capsular contracture: a prospective study of the effect of local antibacterial agents. Plast Reconstr Surg 1986; 77: 919-932.

38 Williams C, Aston S, Rees TD: The effect of hematoma on the thickness of pseudosheaths around silicone implants. Plast Reconstr Surg 1975; 56: 194-198. 
39 Hipps CJ, Raju R, Straith RE: Influence of some operative and postoperative factors on capsular contracture around breast prostheses. Plast Reconstr Surg 1978; 61: 384-389.

40 Chung AP, Sacchini V: Nipple-sparing mastectomy: where are we now? Surg Oncol 2008; 17: 261-266.

41 Gulben K, Yildirim E, Berberoglu U: Prediction of occult nipple-areola complex involvement in breast cancer patients. Neoplasma 2009; 56: 72-75.
Laronga C, Kemp B, Johnston D, Robb GL, Singletary SE: The incidence of occult nipple-areola complex involvement in breast cancer patients receiving a skin-sparing mastectomy. Ann Surg Oncol 1999; 6: 609-613.

43 Petit JY, Le MG, Mouriesse H, et al: Can breast reconstruction with gel-filled silicone implants increase the risk of death and second primary cancer in patients treated by mastectomy for breast cancer? Plast Reconstr Surg 1994; 94: 115-119.

44 Spiegel AJ, Butler CE: Recurrence following treatment of ductal carcinoma in situ with skin-sparing mastectomy and immediate breast reconstruction. Plast Reconstr Surg 2003; 111: 706-711.
45 Simmons RM, Hollenbeck ST, Latrenta GS: Two-year follow-up of areola-sparing mastectomy with immediate reconstruction. Am J Surg 2004; 188: 403-406.

46 Ryu JM, Nam SJ, Kim SW, et al: Feasibility of nipple-sparing mastectomy with immediate breast reconstruction in breast cancer patients with tumor-nipple distance less than $2.0 \mathrm{~cm}$. World J Surg 2016; 40: 2028-2035. 